\title{
Effect of Adding Sildenafil to Clomiphene Citrate Versus Clomiphene Citrate Alone on Endometrial Receptivity in un Ovulatory PCO Patients
}

H.I.Mohamed ${ }^{1}$, M.A. EL-Noury ${ }^{1}$, A.S.Soliman, M.S.Sadek and S.M.Abd-Elazim

Obstetrics , Gynecology Dept., Faculty of Medicine, Benha Univ., Benha, Egypt

E-Mail:Shorooq121@gmail.com

\begin{abstract}
Polycystic ovary syndrome (PCOS) is a common gynecological endocrine disorder of unknown etiology, with a prevalence ranging from 8.7 to $17.8 \%$ in women of reproductive age. Evidence suggests that PCOS phenotype may vary widely and is most commonly observed in the post-pubertal period. The aim of this study is to evaluate the endometrial receptivity (thickness, pattern, Also endometrial blood flow) Furthermore pregnancy rate Previously, patients for unovulatory PCO dealt with by clomiphene citrate Besides sildenafil tablets acquainted orally Likewise contrasted with the individuals treated by clomiphene citrate alone. This similar ponder might have been completed On obstetrics What's more Gynecology Department, Sers el Layan general Hospital, Menoufia Governate, egypt. It incorporated fruitless patients. From the individuals going to the outpatient Also inpatient facility with those finding of PCOS for six months beginning from those time from claiming june 2019 will december 2019. Those endometrial thickness might have been statistically huge higher to gathering (A) Concerning illustration $46 \%$ needed endometrial thickness (7-10) the place to bunch (B) 56\% required endometrial thickness (3-6). Those mono-laminar endometrial design might have been more pervasive to both gatherings half What's more $54 \%$ On gatherings (A) \& (B) individually. No statistically critical distinction discovered Eventually Tom's perusing correlation between two patients' gatherings Similarly as views endometrial example. The utilization from claiming sildenafil Similarly as an enhancer from claiming endometrial thickness serves patients for PCOS infertility, and counteracts poor people impact about clomiphene alone because of dainty endometrium. Sildenafl fundamentally expanded uterine blood flow for anovulatory patients of PCOS with clomiphene citrate disappointment. Sildenafl also expanded pregnancy rate to patients for PCOS and succeed the impact from claiming clomiphene alone. Further investigations ought further bolstering blanket this issues later on may be prescribed.
\end{abstract}

Keywords: PCOS, Sildenafl, Clomiphene, Anovulatory, Endometrial.

\section{Introduction}

Fruitlessness may be for the most part characterized Concerning illustration those failure of a few with consider inside An specific period that is normally person year, duration of the time may be seen Concerning illustration those adversary What's more regularly the few feels a feeling from claiming individual reduction Also disappointment. Polycystic ovarian syndrome (PCOS) will be those commonest reason for unovulatory fruitlessness [1].

Polycystic ovary syndrome (PCOS) will be a as a relatable point gynecological endocrine issue from claiming obscure etiology, for a predominance extending starting with 8.7 on $17.8 \%$ clinched alongside ladies from claiming conceptive period. Confirmation recommends that PCOS phenotype might shift broadly What's more will be mossycup oak ordinarily watched in the post-pubertal period.

Polycystic ovary syndrome may be the essential reason for hyperandrogenism Furthermore oligoanovulation toward those conceptive period What's more will be frequently connected for fruitlessness and clinical Furthermore metabolic issue. To anovulatory ladies for PCOS characterized as stated by those rotterdam agreement (includes every last bit phenotypes but those you quit offering on that one characterized by those affiliation of hyperandrogenism with ultrasonography (US) findings); clomiphene citrate (CC) medicine will be those to start with decision for ovulation incitement [2].
Clomifene, otherwise called clomiphene, is An prescription used to treat fruitlessness to ladies who don't ovulate. This incorporates the individuals who need polycystic ovary syndrome. Clomifene might have been affirmed to restorative utilization in the united states over 1967. It may be on the planet wellbeing association's rundown about vital Medicines, the The majority viable Furthermore sheltered drugs necessary On An wellbeing framework. Utilization brings about An more stupendous opportunity about twins. It may be made by mouth When An day with a course about medicine by enduring five days [3].

In spite of the fact that $\mathrm{cc}$ is simple to utilize Also brings about ovulation for practically patients (57$91 \%$ ), those pregnancy rates need aid frustrating (27$40 \%$ ). It will be due to the unfriendly impacts about cc primarily for nature of the cervical bodily fluid and the endometrial improvement Throughout those incitement [4].

Different methodologies have been received for prompting follicular development and, same time every last bit frameworks about ovarian incitement might move forward the hormonal status of the patient, they don't fundamentally prompt open endometrium suitableness to implantation [5].

Sildenafil will be An sort 5-phosphodiestrase inhibitor that augments vasodilator impact about nitric oxide looking into vascular smooth birch muscles Eventually Tom's perusing keeping those debasement of cGMP. Sildenafil under those sake Viagra may be used to treat erectile brokenness (impotence) over men. 
Sildenafil relaxes muscles of the blood vessels and increments blood stream to specific regions of the body [6].

Sildenafil citrate Might prompt an change done uterine blood stream and, clinched alongside conjunction with oestrogen, it prompts those oestrogeninduced burgeoning of the endometrium. Couple of investigations tended to the utilization of sildenafil should expand endometrial thickness clinched alongside cc invigorated cycles [7].

\section{Subjects and methods}

\subsection{Patients}

This similar consider might have been carried out for obstetrics What's more Gynecology Department, Sers el Layan all Hospital, Menoufia Governate, egypt. It included fruitless patients. From the individuals going to those outpatient Also inpatient facility for those finding from claiming PCOS for six months beginning from the period for june 2019 will december 2019.

\subsection{Ethical consideration}

All participants are volunteers. All of them signed a written informed consent explaining the aim of study before the study initiation. Approval was obtained from ethical committee in Faculty of Medicine, Benha University.

\subsection{Inclusion criteria}

Age: 20-35 years, All patients' husbands with normal semen analysis, Hysterosonography detected the presence of endometrial focal lesions and patients were diagnosed as PCO according to ultrasonographic criteria of PCO and hormonal assay according to Rotterdam ESHRE/ASRM consensus workshop, 2004 as follow: 1. Ultrasonographic criteria more than 12 follicles measuring $2-9 \mathrm{~mm}$ and/or ovarian volume more than $10 \mathrm{~cm}^{3} .2$. Hormonal assay of LH: FSH ratio equal 3:1or more.

\subsection{Exclusion criteria}

Presence of any Organic lesion of uterus, tubes or ovaries such as endometrial polyps, ovarian cysts, leiomyomas, Semen abnormalities, Presence of any medical contraindication to the medication as heart conditions.

\subsection{Method of randomization}

One hundred patients were randomized under two aggregations utilizing a square from claiming six randomization system which may be transformed Eventually Tom's perusing a computer-generated irregular number rundown. The allotment grouping might have been disguised for consecutively numbered, opaque, fixed What's more. Stapled envelopes. This transform might have been ready Toward An statistician.

Patients were classified into 2 groups as follow: Group A (50 patients): Received clomiphene citrate (clomid $50 \mathrm{mg}$ tab) two tablets every 24 hours, for 5 days from day 3 of normal or induced menstrual cycle. Sildenafil (Seldin $25 \mathrm{mg}$ tab), oral tab was given every 12 hours every day starting from day 3 of the period till leading follicle size reaches about 18-20 mm. Group B (50 patients): Received clomiphene citrate (clomid, 50 $\mathrm{mg} \mathrm{tab})$, same dose alone in same manner.

\subsection{N.B}

They study was done on 100 cases of un ovulatory PCO patients till occurrence of pregnancy or after three successive menstrual cycles.

By the end of the study we had (143) and (144) total number of cycles for both group (A) and (B) successively.

\subsection{Ultrasound and Doppler examination}

The sum patients were subjected will full historical backdrop taking through clinical examination Furthermore schedule lab investigations. Serial vaginal ultrasonography were performed altogether subjects during day 3 , day 9 , and each other day till day from claiming follicle extent till heading follicle extent around $18-20 \mathrm{~mm}$ with evaluate endometrial thickness, pattern, uterine corridor blood stream and follicle size. Doppler assessment with recognize uterine corridor blood stream.

\subsubsection{Primary outcome}

Endometrial thickness and pattern. Uterine artery blood flow seen by Doppler.

2.7.2 Secondary outcome:Pregnancy rate by positive HCG in blood after 19 days of leading follicle size from $(18-20 \mathrm{~mm})$.

\subsection{Statistical analysis}

Data were collected throughout history, basic clinical examination; laboratory investigations and outcome measures coded, entered and analyzed using Microsoft Excel software. The data collected were tabulated and analyzed by SPSS (statistical package for social science) version 25 (Armonk, NY: IBM Corp) on IBM compatible computer.

\section{Results}

Mean of age in Group (A) was $27.64 \pm 4.365$ and in Group (B) was $27.34 \pm 3.915$ years. Comparison between two patients' groups shows that means of age were nearly equal between both groups with no statistically significant difference ( $p>0.05$ ) Table (1).

Mean of BMI in Group in both groups was $28.10 \pm$ 1.854 .Comparison between two patients' groups shows that mean of BMI of both groups is statistically non-significant ( $\mathrm{p}>0.05)$ Table (2).

Mean of No. of follicle in Group (A) is $1.61 \pm$ 1.597 and in Group (B) is $1.082 \pm 1.202$. Comparison between two patients' groups shows that means of No. of follicle is nearly equal between both groups with statistically non-significant difference $(\mathrm{p}<0.05)$ Table (3). 
Mean of Uterine artery RI in Group (A) was $8.45 \pm$ 0.25 and in Group (B) was $8.90 \pm 0.134$. Comparison between two patients' groups shows that mean of Uterine artery RI of group (A) was highly statistically significant lower $(\mathrm{p}<0.000)$ Table (4).

Endometrial thickness was statistically significant higher in group (A) as $41 \%$ had Endometrial thickness (7-11) where in group (B) $58 \%$ had Endometrial thickness $(<7)$ Table (5)

Mono-laminar endometrial pattern was more prevalent in both groups $(53 \%)$ and $(81 \%)$ in groups
(A) \& (B) respectively. There is statistically significant difference found by comparison between two patients' groups as regards Tri-Laminar endometrial pattern $(38 \%) \&(24 \%)$ group $(\mathrm{A}) \&(\mathrm{~B})$ respectively Table (6).

Pregnancy test was more negative in both groups $70 \%$ and $92 \%$ in groups (A) \& (B) respectively. Statistically significant difference found by comparison between two patients' groups as regards pregnancy test result Table (7).

Table (1) Comparison between two patients' groups as regards age.

\begin{tabular}{lcccccccc}
\hline Age & \multicolumn{9}{c}{ Groups } & Group (B) & \multicolumn{1}{l}{ T-Test } & P-value \\
\hline & \multicolumn{3}{c}{ Group (A) } & \multicolumn{1}{c}{ t } \\
\hline Range & 20 & - & 35 & 20 & - & 36 & 0.366 & 0.715 \\
Mean \pm SD & 27.64 & \pm & 4.265 & 27.34 & \pm & 3.915 & \\
\hline
\end{tabular}

Table (2) comparison between two patients' groups as regards BMI.

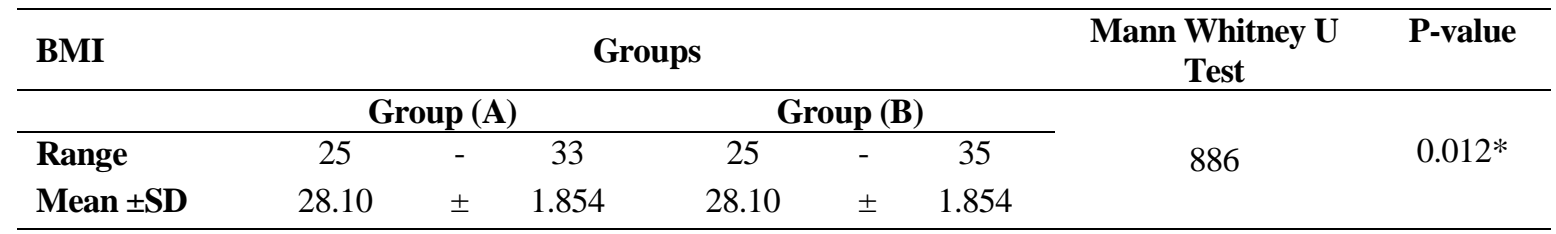

Table (3) Comparison between two patients' groups as regards No. of follicle through the three successive cycles.

\begin{tabular}{lcccccccc}
\hline No. of follicle & \multicolumn{4}{c}{ Groups } & \multicolumn{3}{c}{ Group (B) } & \multicolumn{3}{c}{ T-Test } \\
\hline Range & \multicolumn{1}{c}{ Group (A) } & \multicolumn{1}{c}{ t } & - & 4 & 0 & - & 4 & \multirow{2}{*}{ P-value } \\
Mean \pm SD & 1.61 & \pm & 1.597 & 1.082 & \pm & 1.202 & -0.162 & 0.443 \\
\hline
\end{tabular}

Table (4) Comparison between two patients' groups as regards Uterine artery RI through the three successive cycles .

\begin{tabular}{|c|c|c|c|c|c|c|c|c|}
\hline $\begin{array}{l}\text { Uterine } \\
\text { artery RI }\end{array}$ & \multicolumn{6}{|c|}{ Groups } & $\begin{array}{c}\text { Mann Whitney U } \\
\text { Test }\end{array}$ & P-value \\
\hline & \multicolumn{4}{|c|}{ Group (A) } & & up (B) & \multirow{3}{*}{729} & \multirow[b]{3}{*}{$0.000 * *$} \\
\hline Range & 8.00 & - & 8.80 & 8.7 & - & 9.2 & & \\
\hline Mean \pm SD & 8.45 & \pm & 0.25 & 8.90 & \pm & 0.134 & & \\
\hline
\end{tabular}

Table (5) comparison between two patients' groups as regards endometrial thickness through the three successive cycles .

\begin{tabular}{|c|c|c|c|c|c|c|}
\hline \multirow[t]{3}{*}{$\begin{array}{l}\begin{array}{l}\text { Endometrial } \\
\text { thickness/mm }\end{array} \\
\end{array}$} & \multicolumn{4}{|c|}{ Groups } & \multicolumn{2}{|c|}{ Chi-Square } \\
\hline & \multicolumn{2}{|c|}{ Group (A) } & \multicolumn{2}{|c|}{ Group (B) } & \multirow[b]{2}{*}{$X^{2}$} & \multirow[b]{2}{*}{ P-value } \\
\hline & $\mathbf{N}$ & $\%$ & $\mathbf{N}$ & $\%$ & & \\
\hline$<7 \mathrm{~mm}$ & 47 & 35 & 84 & 58 & \multirow{4}{*}{22.519} & \multirow{4}{*}{$0.000 *$} \\
\hline 7-11 mm & 55 & 41 & 24 & 17 & & \\
\hline $11-13 \mathrm{~mm}$ & 32 & 24 & 36 & 25 & & \\
\hline Total & 134 & 100 & 144 & 100 & & \\
\hline
\end{tabular}


Table (6) comparison between two patients' groups as regards endometrial pattern through the three successive cycles.

\begin{tabular}{lcccccc}
\hline Endometrial pattern & \multicolumn{3}{c}{ Groups } & \multicolumn{3}{c}{ Ghi-Square } \\
\cline { 2 - 5 } & \multicolumn{2}{c}{ Group (A) } & Group (B) & & \\
& N & \% & N & \% & X & P-value \\
Mono-Laminar & 53 & 40 & 81 & 56 & & \\
Bi-Laminar & 30 & 22 & 39 & 27 & 16.40 & 0.000 \\
Tri-Laminar & 51 & 38 & 24 & 17 & & \\
Total & 134 & 100 & 144 & 100 & & \\
\hline
\end{tabular}

Table (7) comparison between two patients' groups as regards Pregnancy test.

\begin{tabular}{|c|c|c|c|c|c|c|}
\hline \multirow[t]{3}{*}{$\begin{array}{l}\text { Pregnancy } \\
\text { test }\end{array}$} & \multicolumn{4}{|c|}{ Groups } & \multicolumn{2}{|c|}{ Chi-Square } \\
\hline & \multicolumn{2}{|c|}{ Group (A) } & \multicolumn{2}{|c|}{ Group (B) } & \multirow[b]{2}{*}{$\mathbf{X}^{2}$} & \multirow[b]{2}{*}{ P-value } \\
\hline & $\mathbf{N}$ & $\%$ & $\mathbf{N}$ & $\%$ & & \\
\hline -ve & 35 & 70 & 46 & 92 & & \\
\hline $1^{\text {st }}$ Cycle & 5 & 10 & 1 & 2 & & \\
\hline $2^{\text {nd }}$ Cycle & 4 & 8 & 1 & 2 & 7.960 & 0.046 \\
\hline $3^{\text {rd }}$ Cycle & 6 & 12 & 2 & 4 & & \\
\hline Total & 50 & 100 & 50 & 100 & & \\
\hline
\end{tabular}

\section{Discussion}

Medicine from claiming fruitlessness in ladies with PCOS comprises from claiming lifestyle adjustment and utilization of clomiphene citrate (CC), exogenous gonadotropins, laparoscopic ovarian surgery, What's more in vitro treatment (IVF). "around these approaches, CC, those first-line alternative for ovulation incitement (OI), need favorable element for low expense What's more not difficult organization [8].

Clomiphene may be a non-steroidal triphenylethylene subordinate distantly identified with diethylstilbestrol. It goes about Likewise An particular estrogen receptor modulator (SERM), comparative will tamoxifen Also raloxifene. Constantly on three medications would aggressive inhibitors for estrogen tying should estrogen receptors (ERs) and have blended anguishing Also adversary activity, depending upon those target tissue [3].

Same time it may be broadly acknowledged that the endometrium is a key figure for fruitful implantation Furthermore to Building An solid pregnancy, slants are separated Similarly as to which parameter may be suiting best for foreseeing An sure result Throughout cycles of helped propagation cost. So, this similar consider pointed to assess the endometrial receptivity (thickness, pattern, Furthermore endometrial blood flow) and pregnancy rate Previously, patients with unovulatory PCOS dealt with Toward clomiphene citrate Also sildenafil tablets presented orally Similarly as contrasted with the individuals treated Eventually Tom's perusing clomiphene citrate alone.

Those available consider might have been finished in obstetrics What's more Gynecology Department, Sers el Layan general Hospital, Menoufia Governate, egypt. It might have been included 100 fruitless patients from the individuals going to the outpatient facility for those finding for PCOS for six months beginning starting with the time from claiming june 2019 with december 2019.

The current ponder demonstrated that the imply of age to assembly (A) might have been $27.64 \pm 4.365$ What's more over one assembly (B) might have been 27. $34 \pm 3.915$ quite some time. Examination between two mulled over aggregations demonstrated that method for period were About equivalent for no statistically critical Contrast $(\mathrm{P}>0.05)$.

These outcomes were in understanding for that for [4] who intended Cross-Sectional, Non-Randomized ponder should demonstrate those impact of including sildenafil to clomiphene citrate versus clomiphene citrate alone on endometrium On unexplained infertility, Furthermore found comparable effects in regards period for both 2 contemplated bunches.

The display contemplate demonstrated that the intend for BMI over assembly (A) might have been 28 . $10 \pm 1.854$ Furthermore done gathering (B) might have been $29.74 \pm 3$. 263. Correlation the middle of two examined bunches demonstrates that imply from claiming form impostor list (BMI) from claiming gathering (A) might have been statistically critical higher $(\mathrm{P}<0.05)$.

These effects were for understanding with these from claiming [9] who concentrated on including sildenafil vaginal gel to clomiphene citrate to fruitless ladies for former clomiphene citrate disappointment because of dainty endometrium Furthermore discovered An statistically noteworthy Contrast viewing BMI.

Those current consider demonstrated that those intend from claiming no. Of follicle clinched alongside 
gathering (A) might have been $1.76 \pm 1.153$ What's more over bunch (B) might have been 1. $68 \pm 1.253$. Examination between two concentrated on bunches indicates that method for no. About follicle were About rise to between both aggregations for no statistically critical distinction $(\mathrm{P}>0$. 05).

These outcomes were comparative to that news person Eventually Tom's perusing [10] who structured a randomized controlled trial regarding sildenafil citrate adjuvant medication Previously, ladies with polycystic ovary syndrome Emulating clomiphene disappointment.

Those available examine indicated that the imply of uterine corridor safety list (RI) clinched alongside gathering (A) might have been $8.45 \pm 0.25$ What's more for bunch (B) might have been 8. $90 \pm 0.134$. Examination between two examined Assemblies demonstrates that intend about uterine corridor ri from claiming bunch (A) might have been profoundly statistically noteworthy easier $(\mathrm{P}<0.001)$.

These comes about were in understanding for that about [9] who utilized doppler ultrasonography with measure the imperviousness list Concerning illustration an pointer about uterine blood flow to both uterine courses. With s were as of the sildenafl vaginal gel, the uterine corridor imperviousness list dropped ( $\mathrm{P}$ quality $=0$. 002) demonstrating a noteworthy decrease done blood flow safety in the uterine veins.

Those present examine indicated that those endometrial thickness might have been statistically critical higher over one assembly (A) as $46 \%$ required endometrial thickness $(7-10 \mathrm{~mm})$ which imply that those sildenafil impact on the endometrium thickness might have been mostly through its impact with evade the vicinity of a (thin) endometrium, (i. E. , less $7 \mathrm{~mm}$ ) the place in assembly (B) $56 \%$ required endometrial thickness (3-6mm); this Contrast is statistically significant, P-value $=0.015$.

Another comparable consider Eventually Tom's perusing [4] discovered that the endometrial thickness over assembly An (clomiphene + sildenafil) 44 patients $(80.0 \%$ ) have endometrium of $7-13 \mathrm{~mm}$, which may be those best. Thickness that favors pregnancy, while best 32 patients $(59.2 \%)$ indicate comparative thickness to gathering $\mathrm{b}$ (clomiphene alone); this Contrast may be statistically critical $(\mathrm{P}<0.05)$.

Those introduce consider indicated that the bilaminar \& trilaminar endometrial design were exhibit together done both aggregations Likewise half Furthermore 40\% Previously, aggregations (A) \& (B) individually. Statistically critical Contrast discovered Toward examination between two examined bunches as respects endometrial design.

However, [4] discovered that those endometrial design required done 52 patients $(92.7 \%)$ a multilayered endometrium over one assembly A, same time the same example might have been introduce clinched alongside 19 patients (42. 6\%) clinched alongside bunch $b$.
The present consider indicated that the pregnancy test might have been additional negative in gathering (B); 46 patients (92\%) Furthermore 41 patients $(82 \%)$ On aggregations (A) \& (B) separately. Statistically critical Contrast discovered by examination the middle of two concentrated on bunches Similarly as views pregnancy test aftereffect.

[4] news person that the pregnancy rates Previously, one assembly A, were 13 cases (23. 6\%) clinched alongside total, situations were primarily On multilayered endometrium to $100 \%, 11$ patients got pregnant same time. Indicating the inward hypoechogenic blood stream zone, same time no pregnancy might have been recorded done endometrium thicker over $13 \mathrm{~mm}$, non-multilayered endometrium, and the sub-endometrial blood stream zone. On the other side, the downright pregnancy rate clinched alongside bunch $\mathrm{b}$ (clomiphene best group) might have been 3 situations (5. 5\%), they happened primarily to An 7-13 mm thickness On the whole cases, Additionally Previously, a multilayered endometrium altogether cases, Furthermore 2 situations out of the 3 pregnancy situations struck them with those internal hypoechogenic blood stream zone; this distinction is statistically huge $(\mathrm{P}<0.05)$.

\section{Conclusion}

The utilization for sildenafil Likewise a enhancer of endometrial thickness serves patients with PCOS infertility, What's more counteracts poor people impact for clomiphene alone because of slim endometrium. Sildenafl altogether expanded uterine blood flow done anovulatory patients of PCOS for clomiphene citrate disappointment. Sildenafl also expanded pregnancy rate in patients of PCOS What's more succeed those impact about clomiphene alone. Further investigations ought to disguise this issues later on will be prescribed.

\section{References}

[1] K. L. Rooney, \& A. D. Domar, The relationship between stress and infertility. Dialogues in clinical neuroscience, Vol. 20, (1), PP. 41-49, 2018.

[2] A.S.Melo,R. A. Ferriani, \& P. A. Navarro, Treatment of infertility in women with polycystic ovary syndrome: approach to clinical practice. Clinics, Vol.70 (11), PP. 765-769, 2015.

[3] E. Seli, A. Arici, \& R. Barbieri, Ovulation induction with clomiphene citrate. UpToDate. Retrieved February, Vol. 1(5), PP.35-65, 2017.

[4] A. M. A. Hamid, \& A. RATEB, Effect of Adding Sildenafil to Clomiphene Citrate versus Clomiphene Citrate alone on Endometrium in Unexplained Infertility: Cross-Sectional, NonRandomized Study. Obstet Gynecol Int J,Vol.7(2), PP. 243-252, 2017.

[5] A. Heger, M. Sator, \& D. Pietrowski, Endometrial receptivity and its predictive value for IVF/ICSIoutcome. Geburtshilfe und Frauenheilkunde, Vol.72,(08),PP. 710-715, 2012.

[6] G. Butrous, The role of phosphodiesterase inhibitors in the management of pulmonary 
vascular diseases. Global Cardiology Science and Practice, Vol. 3, PP. 42-56, 2014.

[7] R. D. Firouzabadi, R. Davar, F. Hojjat, \& M. Mahdavi, Effect of sildenafil citrate on endometrial preparation and outcome of frozenthawed embryo transfer cycles: a randomized clinical trial. Iranian journal of reproductive medicine, Vol. 11(2), PP. 151, 2013.

[8] J. Rojas, M. Chávez, L. Olivar, Polycystic ovary syndrome, insulin resistance, and obesity: navigating the pathophysiologic labyrinth. International journal of reproductive medicine, Vol.25, PP.69-75,2014.
[9] A. N. Fetih, D.M. Habib,I. I. Abdelaal, Adding sildenafil vaginal gel to clomiphene citrate in infertile women with prior clomiphene citrate failure due to thin endometrium: a prospective self-controlled clinical trial. Facts, views \& vision in ObGyn, Vol. 9, ( 1), PP. 21, 2017.

[10]S. Ashoush, \& A. Abdelshafy, Sildenafil citrate adjuvant treatment in women with polycystic ovary syndrome following clomiphene failure: A randomized controlled trial. ebwhj.journals, Vol. 9,(3), PP. 487-493, 2019. 